\title{
Vị trí, vai trò của biểu tình, quyền biểu tình trong xã hội dân chủ, pháp quyền
}

\author{
Đặng Minh Tuấn* \\ Khoa Luật, Đại học Quốc gia Hà Nội, 144 Xuân Thủy, Cầu Giấy, Hà Nội, Việt Nam \\ Nhận ngày 25 tháng 3 năm 2017 \\ Chỉnh sửa ngày 24 tháng 4 năm 2017; Chấp nhận đăng ngày 28 tháng 6 năm 2017
}

\begin{abstract}
Tóm tắt: Ở nước ta vẫn còn có rất nhiều quan niệm, cách nhìn, cách ứng xử khác nhau về biểu tình và quyền biểu tình của công dân, thậm chí coi biểu tình là những hành vi có hại đối sự phát triển, chính thể và sự ổn định chính trị - xã hội. Bài viết này phân tích làm rõ vị trí, vai trò không thể thiếu của biểu tình trong xã hội dân chủ, pháp quyền.
\end{abstract}

Từ khóa: Biểu tình, quyền biểu tình, dân chủ, pháp quyền.

Ở Việt Nam, quyền biểu tình mới chỉ được ghi vào Hiến pháp, nhưng chưa được điều chỉnh bằng một văn bản luật trong nhiều năm qua. Việc ban hành luật về biểu tình đã được đưa vào chương trình xây dựng luật, pháp lệnh, giao cơ quan chủ trì soạn thảo, nhưng đã nhiều lần bị trì hoãn trong việc trình Quốc hội thảo luận, xem xét. Trong quá trình thảo luận về dự án luật này, có rất nhiều quan niệm, cách nhìn nhận khác nhau, chưa đầy đủ và đúng đắn về vị trí, vai trò của biểu tình, quyền biểu tình. Một mặt, biểu tình, quyền biểu tình vẫn chưa được thừa nhận đầy đủ trong đời sống nhà nước và xã hội. Mặt khác, một số người lo ngại việc thực hiện quyền biểu tình có thể dẫn đến những hệ lụy tiêu cực như bạo lực, thiếu kiểm soát. Bài viết này làm rõ biểu tình, quyền biểu tình có vị trí, vai trò không thể thiếu trong đời sống nhà nước và xã hội, đồng thời phân tích rõ các giới hạn của quyền biểu tình trong xã hội dân chủ và

\footnotetext{
*ĐT.: 84-978796682.

Email: tuandangvnu@gmail.com https://doi.org/10.25073/2588-1167/vnuls.4078
}

pháp quyền nhằm bảo đảm biểu tình diễn ra một cách hòa bình, không xâm phạm đến các lợi ích, trật tự công cộng và quyền, lợi ích của người khác.

\section{Vị trí, vai trò của biểu tình, quyền biểu tình trong đời sống nhà nước và xã hội}

Biểu tình là hành vi của công chúng để bày tỏ nguyện vọng một cách công khai, hòa bình, bất bạo động về một vấn đề nào đó đối với cơ quan công quyền để bảo đảm lợi ích công và quyền, lợi ích của các nhóm công chúng khác [1].

\section{- Quyền biểu tình là một cách thức để công dân} thể hiện và thực thi quyền lực của mình

Biểu tình là một hiện tượng trong xã hội từ khi có nhà nước. Hành động biểu tình vẫn cứ tồn tại mặc cho nhà nước có thừa nhận nó hay không. Biểu tình góp phần bày tỏ tiếng nói của người dân. Khi mà xã hội vẫn còn sự bất bình đẳng thì đây là đòi hỏi khách quan. Vì vậy, nhà 
nước không thể ngăn cản biểu tình như trong thời đại các nhà nước chuyên chế. Hành động biểu tình tồn tại một cách dai dẳng trong đời sống kinh tế xã hội, đến một thời điểm nhất định nó trở nên phổ biến. Nhà nước nhận thức được tầm quan trọng và sức ảnh hưởng to lớn không chỉ đến kinh tế mà cả chính trị, xã hội. Từ đó, nhà nước buộc phải thừa nhận và nâng chúng lên thành luật, nhằm ổn định trật tự xã hội và áp đặt ý chí lên các giai cấp khác nhằm điều chỉnh hệ tư tưởng theo đúng quỹ đạo của mình.

Ngày nay, quyền biểu tình là một trong những quyền tự do cơ bản của công dân được pháp luật quốc tế và pháp luật của hầu hết quốc gia trên thế giới thừa nhận. Trong các xã hội dân chủ, công dân có quyền biểu tình như một cách thức thể hiện và thực thi quyền lực của mình. Quyền biểu tình là vũ khí đấu tranh mạnh nhất của người dân sau khi tất cả các biện pháp giải quyết bằng thủ tục pháp lý khác không mang lại sự hài lòng cho họ.

Biểu tình là một hoạt động hợp pháp và hết sức thông thường ở xã hội văn minh; là biện pháp hữu hiệu để nhân dân bảo vệ quyền lợi chính đáng của mình và giải tỏa ức chế; là một hình thức hợp lý để công dân bày tỏ chính kiến, góp phần xây dựng nhà nước và thúc đẩy sự tiến bộ, công bằng của xã hội. Trách nhiệm của các cơ quan nhà nước là phải tôn trọng và bảo vệ công dân thực hiện quyền biểu tình.

Thực hiện quyền biểu tình xuất phát từ tư tưởng "lấy dân là gốc", từ bản chất chính trị của chế độ dân chủ nhân dân. Biểu tình là một trong những phương thức thực hiện quyền tự do, dân chủ, góp phần giải quyết các vấn đề xã hội, giảm bức xúc trong nhân dân. Thông qua hoạt động biểu tình người dân được quyền nói lên những quan điểm của mình một cách công khai và mạnh mẽ nhất đối với các chủ thể Nhà nước. Sự tự do dân chủ thể hiện ở chỗ người dân không chỉ dừng lại ở việc nói lên các quan điểm suy nghĩ của mình, mà trong những trường hợp cụ thể họ có thể đấu tranh thông qua hoạt động biểu tình làm cho các chủ thể khác đáp ứng quyền lợi chính đáng của mình.
Việc thực hiện quyền biểu tình cũng là điều kiện, bảo đảm cho công dân thực hiện các quyền cơ bản khác như quyền tự do hội họp, tự do ngôn luận. Biểu tình về bản chất là một hình thức hội họp - một cuộc họp đông người để bày tỏ quan điểm (ủng hộ hoặc phản đối) của một bộ phận công chúng về một vấn đề nào đó. Tương tự, biểu tình cũng là một trong những hình thức thể hiện của quyền tự do ngôn luận, vì mục đích của biểu tình là để chuyển tải thông điệp chung của những người biểu tình đến nhà nước và xã hội [2].

Việc khẳng định biểu tình là quyền cơ bản của công dân đặt ra các nghĩa vụ của nhà nước trong việc tôn trọng, bảo vệ và thực thi quyền biểu tình. Việc ban hành một đạo luật về biểu tình, quyền biểu tình, tổ chức và bảo đảm các điều kiện cần thiết để công dân thực hiện quyền biểu tình là những nghĩa vụ cơ bản của nhà nước trong việc bảo đảm quyền biểu tình của công dân.

- Biểu tình là một trong nhũng kênh thông tin tốt nhất để nhà nước nắm bắt tâm tu nguyện vọng của người dân, tù đó nhà nước xủ lý, giải quyết các vấn đề của nhà nước, người dân.

Biểu tình là hình thức biểu đạt chính kiến tư tưởng tình cảm nhưng không phải chung chung hay đối với cá nhân cụ thể, mà đối với một chính sách nào đó của nhà nước hay trước một sự kiện nào đó xảy ra mà họ muốn xã hội, nhà nước quan tâm giải quyết.Thông qua hoạt động biểu tình, người dân sẽ phản ánh một cách trung thực những quan điểm (bức xúc) của họ đối với những chính sách được ban hành. Khi những chủ trương, đường lối không được lòng dân thì biểu tình là một cách để nhà nước nhận ra những điểm chưa hợp lý. Nhà nước càng lắng nghe ý kiến của dân một cách tích cực thì người dân cũng có những phản ứng tích cực hơn. Nếu chủ trương của Đảng cầm quyền và chính sách pháp luật của nhà nước không đáp ứng hay cản trở sự phát triển, ảnh hưởng đến đời sổng, công việc làm ăn mà ý kiến của người dân không được các cấp thẩm quyền lắng nghe, tiếp thu, chính sửa... thì người dân sẽ tiếp tục có những phản ứng bằng nhiều cách khác nhau, nhiều 
mức độ khác nhau, thậm chí có những phản ứng rất tiêu cực, để lại những hậu quả nặng nề.

Lắng nghe tâm tư, nguyện vọng của nhân dân, giải quyết thích đáng các yêu cầu của nhân dân trong các cuộc biểu tình đem lại tác dụng tích cực, tạo sự ồn định để phát triển, giữ vững ổn định chính trị - xã hội, tránh làm đảo lộn bình yên cuộc sống, tránh làm xấu đi môi trường xã hội, tránh làm triệt tiêu những yếu tố tạo môi trường phát triển lành mạnh, bền vững về chính trị, kinh tế, xã hội. Biểu tình là một phương tiện đắc lực để khắc phục tệ quan liêu - căn bệnh cố hữu của bộ máy chính quyền. Qua biểu tình và giải quyết các yêu cầu của đám đông biểu tình, cơ quan công quyền có thể rút ra những bài học, kinh nghiệm giải quyết mâu thuẫn trong mỗi trường hợp cụ thể. Cơ quan nhà nước có thể nhận thây những khiếm khuyết trong các quá trình thực thi quyền lực, có thể phải chỉnh sửa các quyết định cho phù hợp với yêu cầu của đời sống xã hội, phải nâng cao hơn tinh thần trách nhiệm trước nhân dân, trước xã hội. Trong trường hợp, nếu yêu cầu, nguyện vọng của đám đông biểu tình là chính đáng, đúng pháp luật, nhưng lại bị phía cơ quan công quyên từ chối, không giải quyết và nếu phía chính quyền coi biểu tình, một quyền tự do chính đáng của công dân là hành động trái pháp luật, coi đó là hoạt động chống phá chính quyền, gây rối, bạo loạn, để rồi sử dụng bạo lực đán áp, thì những rắc rối của ngày hôm nay có thể sẽ trở thành "quả bom nổ chậm" cho một tương lai không xa, có thể dẫn đến những hậu họa nghiêm trọng, gây bất ổn định chính trị - xã hội, hoặc làm vô hiệu hóa hoạt động của một số cơ quan công quyền ở địa phương, cơ sở. Cơ quan công quyền nếu thực sự cầu thị và muốn làm tròn bốn phận, lãnh đạo phải biết tận dụng hoạt động biểu tình như một chiếc cầu nối với nhân dân, làm nguồn cung cấp thông tin thực tế từ cơ sở, vốn dĩ hay bị bưng bít bởi bộ máy quản lý cấp dưới. Nếu các cơ quan có trách nhiệm vào cuộc giải quyết biểu tình nếu không có bước đi, thái độ, biện pháp đúng, có thể đẩy cuộc biểu tình từ chổ hòa bình ngả sang hướng đám đông sử dụng bạo lực. Khi đó, các cơ quan có trách nhiệm sẽ mất kiểm soát; mâu thuẫn, xung đột khồng những không được được xử lý tốt mà còn có thể dẫn đến những bất lợi cho thể chế chính trị, có thể gây ra sức tàn phá lớn về vật chất, niềm tin và về con người.

Biểu tình có thể đóng vai trò tích cực hoặc tiêu cực trong đời sống xã hội phụ thuộc vào những yêu cầu, nguyện vọng của đám đông biểu tình, bản chất và cường độ của mâu thuẫn và cách giải quyết mâu thuẫn. Về phía người dân, kết quả giải quyết các nguyện vọng, yêu cầu của người dân sẽ làm tăng lòng tin, hoặc cũng có thể làm mất lòng tin của người dân đối với chính quyền, tùy theo những nguyện vọng chính đáng của đám đông có được tiếp thu, giải quyết đến đâu. Trong trường những yêu cầu của người dân là không chính đáng, sau khi được giải giải thích, họ thấy được phần trách nhiệm của mình (như thiếu hiểu biết về chính sách, pháp luật, hoặc do thông tin sai lệch), họ sẽ thấy phải tuân thủ nghiêm túc hơn. Ngược lại, nếu nguyện vọng, yêu cầu của người dân là chính đáng, được chính quyền chấp thuận, giải quyết, họ thấy được thỏa mãn, tin tưởng vào cơ quan quyền lực của dân hơn. Tóm lại, trong cả 2 trường hợp, sẽ thắt chặt quan hệ giữa "người đầy tớ" với "ông chủ". Khi đó, sẽ nâng cao ý thức trách nhiệm làm chủ quyền lực của công dân và trách nhiệm của công dân với chính quyền.

Nếu cản trở đối với biểu tình và thực hiện quyền biểu tình của công dân xuất phát từ ý muốn được "yên ổn", coi biểu tình như một điều "phạm húy", hoặc phía chính quyền coi các cuộc biểu tình không do các cơ quan Nhà nước tổ chức là bất hợp pháp, là cố tình gây rối, hoặc quanh co, không dám gọi đúng tên... để rồi ngăn cản bằng mọi cách, sẽ là cản trở tự do công dân và đảm lợi ích công dân theo pháp luật, làm suy yếu vai trò nhà nước.

Vị trí, vai trò cơ bản của quyền biểu tình đã được nêu rõ trong Hướng dẫn của Tổ chức về An ninh và Hợp tác ở Châu Âu (OSCE) về tự do hội họp hòa bình như sau: Quyền này tạo điều kiện giao lưu đối thoại trong xã hôi dân chủ, cũng như giữa xã hội dân chủ, các thủ lĩnh chính trị và chính phủ, giúp gia tăng khả năng giao tiếp với thế giới nói chung, và ở những nước mà các phương tiện truyền thông bị hạn chế hoặc bị ngăn cấm, tự do hội họp là rất quan 
trọng cho những người muốn thu hút sự chú ý đến các vấn đề của địa phương.

\section{- Biểu tình là một cách để nhân dân kiểm soát quyền lực nhà nước}

Biểu tình là phương thức để nhân dân thực hiện quyền kiểm tra, giám sát của mình và thực hiện quyền làm chủ của nhân dân. Biểu tình hướng tới bảo vệ quyền, lợi ích hợp pháp của tổ chức, cá nhân và bảo đảm pháp luật được thực thi nghiêm minh, bảo đảm pháp quyền nhằm xây dựng nhà nước pháp quyền. Thông qua việc thực hiện quyền này, công dân có thể góp phần tích cực vào hoạt động quản lý nhà nước và xã hội, đồng thời bảo vệ quyền lợi chính đáng của mình.

Không cho biểu tình là tước bỏ một phần quyền giám sát của nhân dân đối với nhà nước. Sự hạn chế quyền lực này của nhân dân thông qua cơ chế tự do ngôn luận, tự do hội họp, tự do thông tin, bàn bạc tranh luận, biểu tình. Nhân dân có thể kiểm tra, theo dõi việc thực hiện quyền lực nhà nước, nếu không đáp ứng, nhân dân có thể sẽ chế ngự bằng việc biểu tình phản đối hoặc thay đổi chính phủ một cách hòa bình hoặc phương thức cuối cùng là nổi dậy bằng khởi nghĩa, đấu tranh vũ trang để đạp đồ.

Một trong những hình thức thể hiện dân chủ là việc người dân có quyền tham gia vào công việc của nhà nước. Quyền lợi hợp pháp của nhân dân phải được đặt lên hàng đầu. Chủ trương và chính sách có liên quan đến người dân thì người dân có quyền được biết và đóng góp ý kiến, Nhà nước có trách nhiệm tạo mọi điều kiện có thể để nhân dân thực hiện quyền của mình. Biểu tình là một hình thức để nhân dân thực hiện sự giám sát đối với hoạt động của Nhà nước. Nếu người dân không được biểu tình để bày tỏ quan điểm, thể hiện những bức xúc của mình đối với hoạt động của Nhà nước do chính mình lập nên thì chưa thể hiện hết sự dân chủ đó trong xã hội.

\section{Những giới hạn của quyền biểu tình trong xã hôi dân chủ và pháp quyền}

Quyền biểu tình là một quyền cơ bản của công dân. Tuy vậy, việc thực hiện quyền biểu tình luôn được đặt trong các giới hạn nhằm bảo đảm biểu tình diễ்n ra một cách hòa bình, không xâm phạm đến các lợi ích, trật tự công cộng và quyền, lợi ích của người khác.

Biểu tình là hoạt động rất dễ gây trở ngại hoặc rối loạn các hoạt động của nhà nước và cộng đồng, vì thế nhà nước phải điều chỉnh để bảo đảm sự ổn định xã hội - đây chính là để bảo đảm lợi ích công. Đồng thời, các cuộc biểu tình, cho dù có sự tham gia đông đảo nhất, cũng không bao giờ tập hợp được hết và đại diện cho ý chí của toàn bộ dân chúng của một quốc gia. Vì thế, bên cạnh quyền, lợi ích của người biểu tình, nhà nước phải bảo vệ quyền, lợi ích của các nhóm dân chúng khác không tham gia biểu tình. Đó chính là lý do pháp luật quốc tế và pháp luật của các quốc gia đều quy định những điều kiện và hạn chế với việc biểu tình [3]. Nói cách khác, quyền biểu tình không phải là quyền tuyệt đối.

Theo 21 Công ước Quốc tế về các quyền dân sự và chính trị năm 1996, quyền tự do hội họp hòa bình không phải là các quyền tuyệt đối, việc thực hiện quyền này có thể bị hạn chế "do pháp luật quy định và là cần thiết trong một xã hội dân chủ, vì lợi ích quốc gia, an toàn và trật tự công cộng, và để bảo vệ sức khỏe và đạo đức xã hội hoặc bảo vệ quyền và tự do của những người khác". Ngoài ra, Công ước cũng quy định biểu tình nhằm mục đích tuyên truyền cho chiến tranh hoặc vận động cho sự căm thù về dân tộc, chủng tộc hay tôn giáo bao gồm việc khích động phân biệt đối xử, thù hận hay bạo lực (Điều 20) hoặc các hành vi nhằm phá hoại quyền và tự do quy định trong Luật nhân quyền quốc tế (Điều 5) cần được coi là bất hợp pháp. Ngoài ra, báo cáo viên đặc biệt của Liên hợp quốc cũng nhấn mạnh rằng quyền sống và quyền không bị tra tấn hay trừng phạt hoặc đối xử tàn bạo, vô nhân đạo hay hạ nhục cần luôn luôn được nhà nước bảo đảm, bao gồm trong hoàn cảnh thực hành quyền hội họp hòa bình [4]. Luật nhân quyền quốc tế quy định các quyền con người, trong đó có quyền tự do hội họp hòa bình có thể bị tạm đình chỉ trong tình trạng khẩn cấp, tuy nhiên báo cáo viên đặc biệt của Liên hợp quốc thì cho rằng các quyền tự do 
hội họp hòa bình và hiệp hội không nên bị đình chỉ vì "khả năng hạn chế một số quyền nhất định trong Công ước, ví dụ, tự do hội họp, nhìn chung là không phù hợp trong những tình huống như vậy và sự cần thiết của tình hình không thể biện minh được cho sự đình chỉ các quyền ấy" [5].

Biểu tình là quyền của công dân, nhưng không được đe dọa đến sinh hoạt bình thường của cộng đồng, sự tồn vong của nhà nước, của chế độ chính trị. Do đó, biểu tình luôn luôn chỉ được pháp luật cho phép khi nó tiến hành một cách hòa bình. Tính phổ biến trong mọi chế độ dân chủ, biểu tình sử dụng bạo lực đều bị coi là bất hợp pháp. Luật nhân quyền quốc tế cũng chỉ bảo vệ những cuộc hội họp mang tính ôn hòa, nghĩa là những cuộc hội họp phi bạo lực, và khi nào các thành viên tham dự có mục đích ôn hòa - đây là nguyên tắc tiền định [6].

Tuy nhiên, ranh giới giữa biểu tình hòa bình với biểu tình có sử dụng bạo lực cũng chỉ là tương đối, tùy theo quan niệm của mỗi quốc gia. Thí dụ: các hành vi người biểu tình xây tường rào, dùng gạch đá ngăn chặn, to tiếng chửi bới, dùng lời lẽ thô tục lăng mạ... có phải là bạo lực hay không còn tùy quy định của pháp luật mỗi nước có cho phép hay không. Điều này thể hiện rất rõ việc xử lý các hành vi vi phạm pháp luật trong biểu tình thời gian trước và trong cuộc bầu cử nghị viện ở Thái Lan 2/2/2014 hoặc như ở Australia ngày 4/4/2015.

Biểu tình hòa bình có thể dẫn tới biểu tình có sử dụng bạo lục, hoạc đe dọa sủ dụng bạo lục tức là đám động biểu tình đã đi quá giới hạn, tù hơp pháp đến phi pháp, từ chỗ tôn trọng pháp luật đến vi phạm pháp luật, từ biểu tình hòa bình có thể chuyển sang bạo động hoặc bạo loạn, sẽ làm cho tình hình trở lên khó kiểm soát. Khi đó, tình hình sẽ trở lên phức tạp hơn nhiều. Bạo lực có thể nổ ra khi căng thẳng lên cao hoặc do cảnh sát hay quân đội đàn áp. Nhiều cuộc biểu tình lúc đầu diễn ra một cách hòa bình, đúng pháp luật, an ninh trật tự vẫn được duy trì, nhưng sau một thời gian, do nhiều nguyên nhân, từ biểu tình hòa bình, ôn hòa có thể chuyển hướng sang sử dụng bạo lực. Tuy nhiên, biểu tình dù được cho là quyền cơ bản của con người, nhưng bởi biểu tình bao giờ cũng là một tập hợp người, khó tránh khỏi quy luật "hội chứng đám đông" dẫn tới bạo lực vượt ra ngoài khuôn khổ của biểu tình hòa bình nếu không được bảo đảm tiền đề pháp lý loại trừ hội chứng đó. Bạo lực có thể nổ ra khi căng thẳng lên cao. Điều này do nhiều nguyên nhân tùy theo hoàn cảnh: do những đề xuất, mong muốn của người biểu tình chậm được giải quyết, đáp ứng; do những người biểu tình quá nôn nóng dẫn tới không thể kiểm chế, bức xúc cao độ; hoặc do văn hóa kiến thức hiểu biết pháp luật kém của những người biểu tình, nhất là của người cầm đầu, thủ lĩnh biểu tình; hoặc do một số phần tử quá khích; hoặc do một số phần tử xấu, phá hoại xen vào; hoặc do cảnh sát hay quân đội đàn áp... tùy theo hoàn cảnh và các yếu tố về văn hóa và luật pháp... Nếu nhà chức trách không thuyết phục được, đám đông vẫn tỏ ra quyết liệt sử dụng bạo lực, thì khi đó, đòi hỏi nhà chức trách phải sử dụng các lực lượng cần thiết để giải tán cuộc biểu tình.

Ngoài việc đảm bảo biểu tình ôn hòa, các quốc gia trên thế giới còn có nhiều quy định và thực tiễn khác nhau trong việc quy định các điều kiện và hạn chế quyền biểu tình như thủ tục thông báo (hoặc đăng ký) biểu tình, các hành vi bị cấm trong biểu tình, các nghĩa vụ, trách nhiệm của người biểu tình, người tổ chức biểu tình... Để tránh sự lạm dụng trong việc hạn chế quyền biểu tình và các quyền tự do cơ bản khác, pháp luật nhiều nước quy định và thực thi nguyên tắc bất kỳ giới hạn nào được áp dụng phải được quy định trong pháp luật, là cần thiết và cân xứng với mục đích hướng đến.

\section{Kết luận}

Qua những phân tích trên đây, bài viết đã chỉ rõ biểu tình, quyền biểu tình có vị trí, vai trò quan trọng không thể thiếu trong đời sống nhà nước và xã hội, đồng thời việc thực hiện quyền biểu tình cần phải được giới hạn trong những khuôn khổ của nguyên tắc dân chủ và pháp quyền. Những quan điểm, nhận thức này cần phải được quán triệt trong việc xây dựng luật 
biểu tình tránh những nhận thức không đầy đủ, chưa đúng về biểu tình, quyền biểu tình trở thành rào cản cho việc thảo luận và thông qua luật biểu tình trong thời gian tới. Các nghiên cứu tiếp theo nên tập trung phân tích đề xuất một khuôn khổ pháp luật về biểu tình phù hợp với điều kiện, bối cảnh của Việt Nam.

\section{Lời cảm ơn}

Bài viết này được thực hiện trong khuôn khổ đề tài cấp ĐHQGHN, mã số QG 15.63 "Co sở lý luận và thực tiễn xây dựng luật biểu tình ở Việt Nam" từ năm 2015 đến năm 2017 do PGS.TS. Đặng Minh Tuấn chủ nhiệm.

\section{Tài liệu tham khảo}

[1] Đặng Minh Tuấn, Lí luận về biểu tình và quyền biểu tình, Tạp chí Luật học, Đại học Luật Hà Nội, số 3/2016, tr.69-70.
[2] Đặng Minh Tuấn, Lí luận về biểu tình và quyền biểu tình, Tạp chí Luật học, Đại học Luật Hà Nội, số 3/2016, tr.69-70.

[3] Đặng Minh Tuấn, Lí luận về biểu tình và quyền biểu tình, Tạp chí Luật học, Đại học Luật Hà Nội, số 3/2016, tr.62-63.

[4] Báo cáo của Báo cáo viên đặc biệt về các quyền tự do hội họp hòa bình và tự do hiệp hội Maina Kiai trình Hội đồng nhân quyền Liên hợp quốc tại Kỳ họp thứ 20, ngày 21/5/2012 (A/HRC/20/27).

[5] Báo cáo của Báo cáo viên đặc biệt về các quyền tự do hội họp hòa bình và tự do hiệp hội Maina Kiai trình Hội đồng nhân quyền Liên hợp quốc tại Kỳ họp thứ 20, ngày 21/5/2012 (A/HRC/20/27).

[6] Theo Vũ Công Giao, Nguyễn Phú Hải, Nguyễn Anh Đức, Các tiêu chuẩn và hướng dẫn của Liên hợp quốc và OSCE về thực hiện quyền biểu tình, Kỷ yếu Hội thảo khoa học Pháp luật về biểu tình của một số quốc gia và kinh nghiệm cho Việt Nam, Khoa Luật ĐHQGHN, Hà Nội, 18/3/2016, tr.130.

\title{
The Position and Role of Demonstration, Right to Demonstrate in a Democratic Society and the Rule of Law
}

\author{
Dang Minh Tuan \\ VNU School of Law, 144 Xuan Thuy, Cau Giay, Hanoi, Vietnam
}

\begin{abstract}
In Vietnam there still exist different views, different ways of reacting to demonstration and right to demonstrate. Some even consider demonstration to be harmful to the development, regime and social-political stability. This article clarifies the indispensable position and role of demonstration in a democratic society and the rule of law.
\end{abstract}

Keywords: Demonstration, right to demonstrate, democracy, rule of law. 